\title{
High-Temperature Precipitation Design-of-Experiments Simulation in Low-Alloy Cr-Mo-Ni Hot Forging Steel
}

\author{
Roberto Gonzalez-Ojeda ${ }^{1, *(\mathbb{C})}$, Octavio Lozada-Flores ${ }^{1}$, Gonzalo Gonzalez-Reyes ${ }^{2}$ (]) \\ and Jose Manuel Sanchez-Moreno ${ }^{3,4}$ \\ 1 Facultad de Ingeniería, Universidad Panamericana, Augusto Rodin 498, Ciudad de México 03920, Mexico; \\ olozada@up.edu.mx \\ 2 Instituto de Investigaciones en Materiales, Universidad Nacional Autónoma de México, \\ Circuito Exterior S/N, Cd. Universitaria, A. P. 70-360, Coyoacán 04510, Mexico; joseggr@unam.mx \\ 3 CEIT-Basque Research and Technology Alliance (BRTA), Manuel Lardizabal 15, \\ 20018 Donostia-San Sebastián, Spain; jmsanchez@ceit.es \\ 4 Universidad de Navarra, Tecnun, Manuel Lardizabal 13, 20018 Donostia-San Sebastián, Spain \\ * Correspondence: robglez@up.edu.mx; Tel.: +52-5554821600
}

check for updates

Citation: Gonzalez-Ojeda, R.; Lozada-Flores, O.; Gonzalez-Reyes,

G.; Sanchez-Moreno, J.M.

High-Temperature Precipitation

Design-of-Experiments Simulation in Low-Alloy Cr-Mo-Ni Hot Forging Steel. Metals 2021, 11, 1054. https:// doi.org/10.3390/met11071054

Academic Editor:

Bernd-Arno Behrens

Received: 26 May 2021

Accepted: 25 June 2021

Published: 30 June 2021

Publisher's Note: MDPI stays neutral with regard to jurisdictional claims in published maps and institutional affiliations.

Copyright: (c) 2021 by the authors. Licensee MDPI, Basel, Switzerland. This article is an open access article distributed under the terms and conditions of the Creative Commons Attribution (CC BY) license (https:// creativecommons.org/licenses/by/ $4.0 /)$.

\begin{abstract}
The role of alloying elements such as $\mathrm{Cr}$, Mo and Mn on low-alloy 8620 steel during hot forging operations is not yet clear, as, during deformation in the $1000 \sim 1100{ }^{\circ} \mathrm{C}$ temperature range, the austenite grain size remains small, ensuring the capacity of the forged part to be subsequently modified by surface hardening procedures. This work analyzed a deformed bar considering hardness at different geometry zones, along with SEM and TEM microstructures of previous austenite grains and lamellar martensite spacing. Moreover, Thermocalc simulations of $\mathrm{M}_{7} \mathrm{C}_{3}, \mathrm{M}_{23} \mathrm{C}_{6}$ and $\mathrm{MnS}$ precipitation were combined with Design of Experiments (DOE) in order to detect the sensitivity and significant variables. The values of the alloying elements' percentages were drastically modified, as nominal values did not produce precipitation, and segregation at the austenite matrix may have been responsible for short-term, nanometric precipitates producing grain growth inhibition.
\end{abstract}

Keywords: low-alloy steel; precipitation; lamellar spacing; design of experiments

\section{Introduction}

The use of low-alloy steels in hot forging operations is indispensable for the automotive industry, as the low cost of materials used for transmission gears and other structural parts depends on reliable steels that are also capable of surface modification (nitriding, rectifying and burnishing) [1]. In the case of $8620 \mathrm{Ni}-\mathrm{Cr}-\mathrm{Mo}$ low-alloy steel, high-temperature deformation in the $1000 \sim 1100{ }^{\circ} \mathrm{C}$ range is performed using an industrial die press in short periods of time after the steel bar is removed from the furnace (less than $30 \mathrm{~s}$ ) [2].

Though Calphad simulations indicated that, due to the low amount of Cr, Mo, C, Mn and $S$, this steel would not produce precipitation at this temperature range, the initial and final small grain size indicated that the static and dynamic recrystallization mechanisms were slowed down by nanometric precipitates [3], which can only exist if chemical segregation at grain boundaries drastically changes the local amount of the alloying elements.

If only the $\mathrm{Fe}-\mathrm{Cr}-\mathrm{C}$ ternary system is considered, there is a coarsening of $\mathrm{M}_{23} \mathrm{C}_{6}$ precipitates at $780{ }^{\circ} \mathrm{C}$. Different models for the precipitation of this phase have been proposed, observing particles 200 250 $\mathrm{nm}$ in size [4]. Segregation of elements has been documented using three-dimensional atom probe (3DAP) techniques in Fe-Ni-Cr-Mo steels, specifically evaluating the role of V. Small amounts produce $M C, M_{2} C$ and $M_{6} C$, though the lack of $\mathrm{V}$ results in $\mathrm{M}_{23} \mathrm{C}_{6}$. These segregation maps have indicated considerable differences in nominal composition for elements such as $\mathrm{Cr}$ and $\mathrm{Mo}$, with $\mathrm{M}_{23} \mathrm{C}_{6}$ being a Fe-Cr-rich carbide when other particles are also formed [5].

Comparisons between thermodynamic calculation and experimental data have been performed in $\mathrm{Ni}$, Mo and $\mathrm{Cr}$ steels with approximately $0.2 \% \mathrm{C}, 0.3 \% \mathrm{Mn}, 3.5 \% \mathrm{Ni}, 1.8 \%$ 
$\mathrm{Cr}$ and $0.5 \%$ Mo. Ni will produce thinner martensite laminates, forming $\mathrm{Cr}_{23} \mathrm{C}_{6}, \mathrm{Cr}_{7} \mathrm{C}_{3}$ and $\mathrm{Mo}_{2} \mathrm{C}$ precipitates. These particles, from a thermodynamic point of view, disappear at $\sim 800{ }^{\circ} \mathrm{C}$, yet $\mathrm{MnS}$ is present at $1200{ }^{\circ} \mathrm{C}$ [6]. If the alloying elements are increased (316L stainless steel), $\mathrm{M}_{7} \mathrm{C}_{3}$ precipitation in the shape of needles located at grain boundaries can be observed [7]. Similar morphologies have been observed using tempering at $700{ }^{\circ} \mathrm{C}$ in $4 \%$ Cr steels [8]

In the case of $\mathrm{M}_{23} \mathrm{C}_{6}$, Calphad methods have indicated that large amounts of $\mathrm{Cr}, \mathrm{Ni}$, $\mathrm{Mo}$ and $\mathrm{C}$ stabilize this phase at temperatures as high as $1200^{\circ} \mathrm{C}$ [3]. Furthermore, strain also plays a significant role, as high-Cr steels $(12 \%)$ form $\mathrm{M}_{23} \mathrm{C}_{6}$ precipitates during creep at $650 \mathrm{MPa}$ and 10,000 $\mathrm{h} \mathrm{[9]}$, and segregated zones have been observed in stainless 304L steel around $\mathrm{M}_{23} \mathrm{C}_{6}$ precipitates during annealing above $650 \mathrm{C}$; coalescence of particles has also been observed [10].

Grain growth models (steels with $\mathrm{Ti}$ and $\mathrm{Nb}$ ), which consider the previous austenite grain size (PAGS), indicate that between 950 and $1200{ }^{\circ} \mathrm{C}$, small precipitates $(\sim 300 \mathrm{~nm})$ may form [11]. Moreover, austenitizing treatments promote the $\mathrm{M}_{23} \mathrm{C}_{6}$ to $\mathrm{M}_{7} \mathrm{C}_{3}$ transformation in $\mathrm{Cr}-\mathrm{Mo}-\mathrm{V}$ steels, and the packet size of martensite is linearly related to PAGS with trip-like $\mathrm{M}_{23} \mathrm{C}_{6}$ precipitate at the martensite lathe boundaries [12].

Though the 8620 steel has much lower amounts of alloying elements than the steels described above and also lacks $\mathrm{Ti}$ and $\mathrm{Nb}$ as high-temperature precipitation formers, intensive quenching of carburized steels indicated that 8620 presents a three times smaller grain size than 1020 steel. In the as-received form, 1020 has a $23 \mu \mathrm{m}$ grain size, while 8620 has $10 \mu \mathrm{m}$ [13]. As impact toughness is significantly deteriorated by increasing the PAGS size [12] and these steels are used in automotive hot forging applications because of their high toughness, it is evident that PAGS controlling mechanisms must be active at 1000 or $1100^{\circ} \mathrm{C}$ during deformation, with only $\mathrm{Cr}$, Mo or Mn being responsible for the nanometric, short-term precipitation slowing down static and dynamic recrystallization and austenite grain growth. Table 1 summarizes the simulations or analyses of precipitates at high temperatures by the studies just mentioned.

Table 1. Thermocalc simulations and characterization of different steels and precipitate formation at high temperature.

\begin{tabular}{ccc}
\hline Author (et al.) & Steel & Precipitates \\
\hline Zhu [4] & $\mathrm{Cr}-\mathrm{C}$ & $\mathrm{M}_{23} \mathrm{C}_{6}, 200 \sim 250 \mathrm{~nm}$ \\
Wen [5] & $\mathrm{Ni}-\mathrm{Cr}-\mathrm{Mo}$ & Segregation evidence and $\mathrm{M}_{23} \mathrm{C}_{6}$ \\
Park [6] & Nuclear grade Ni-Mo-Cr & $\mathrm{Cr}_{23} \mathrm{C}_{6}, \mathrm{Cr}_{7} \mathrm{C} \mathrm{Mo} \mathrm{M}_{2} \mathrm{C}$, which \\
disappear at $800{ }^{\circ} \mathrm{C}$ \\
Ernst [7] & $316 \mathrm{~L}$ & $\mathrm{M}_{7} \mathrm{C}_{3}$ at grain boundaries \\
Ziyong [8] & $4 \% \mathrm{Cr}$ & $\mathrm{M}_{23} \mathrm{C}_{6}$ while tempering at $700{ }^{\circ} \mathrm{C}$ \\
Prat [9] & $12 \% \mathrm{Cr}$ & Creep at 650 MPa forms $\mathrm{M}_{23} \mathrm{C}_{6}$ \\
Graux [11] & $\mathrm{Ti}+\mathrm{Ni}$ & Small precipitates detected at \\
& & $950 \sim 1200{ }^{\circ} \mathrm{C}$ \\
\hline
\end{tabular}

For steels that require high toughness in the martensite state, PAGS must be low enough to ensure that cracks will not propagate. Reduction of the lamellar spacing in martensite is an additional way to maintain or increase this property [12]. This work analyzed the resulting microstructure of quenched steel after deformation at $1100{ }^{\circ} \mathrm{C}$, in order to verify that the austenite grain size was small and also that the resulting lamellar spacing as a function of strain, being the deformed bar, was large enough to differentiate the microstructure and hardness characteristics at clearly separated points.

Though a high temperature precipitation Thermocalc calculation analysis for this specific low-alloy steel is hard to find in the literature, modified SA508 nuclear grade steels with $\mathrm{Cr}$ contents of 2.5\% [6] indicated that this last element is the main reason for $\mathrm{M}_{23} \mathrm{C}_{6}$ precipitates appearing at temperatures as high as $800^{\circ} \mathrm{C}$. 
On the other hand, micro-segregation and the possible increase in alloy concentration at the grain boundaries at $1100{ }^{\circ} \mathrm{C}$ (diffusion is extremely fast at this temperature) are yet to be analyzed through Thermocalc (or other simulation or experimental methods) as an explanation for grain growth inhibition in these types of steel.

The present work focused on explaining, from a modeling and thermodynamic point of view, the role of carbide-forming elements in low-alloy steels at high temperature by using Thermocalc simulations, while also confirming the results with experimental tests and SEM and TEM characterization, making the short-lived nanometric-sized carbides' presence at $1000^{\circ} \mathrm{C}$ the best hypothesis for grain growth inhibition.

\section{Materials and Methods}

The chemical composition of the 8620 steel used in this work is indicated in Table 2. In order to reproduce hot forging conditions, an 8620 steel bar, $38.1 \mathrm{~mm}$ in diameter (1.5 in) and $44 \mathrm{~mm}$ in length (Figure 1), was heated inside a furnace up to $1100{ }^{\circ} \mathrm{C}$ at a $50{ }^{\circ} \mathrm{C} / \mathrm{min}$ rate, maintained for a $10 \mathrm{~min}$ period, and then deformed with a hydraulic press by compression to a length of $40 \mathrm{~mm}$. Immediately after deformation, the hot bar was submerged in room-temperature water $\left(15^{\circ} \mathrm{C}\right)$ in order to produce martensite, austenite and also bainite at the zones where the cooling rate was not fast enough to cross the Ms limit (the radius of the bar was large enough to observe differences in cooling rates and the resulting microstructure).

Table 2. Nominal composition of 8620 steel [14] (a) and the two-level DOE values for eight alloying elements (mass \%) and temperature (b).

\begin{tabular}{lccccccccc}
\hline Element & Cr & C & Ni & Mo & Mn & Si & S & P & $\mathbf{T}^{\circ} \mathbf{C}$ \\
\hline Min $^{\mathrm{a}}$ & 0.4 & 0.18 & 0.4 & 0.15 & 0.7 & 0.15 & 0 & 0 & - \\
Max $^{\mathrm{a}}$ & 0.6 & 0.23 & 0.7 & 0.25 & 0.9 & 0.35 & 0.04 & 0.035 & - \\
Min $^{\mathrm{b}}$ & 4 & 1.6 & 0.55 & 0.2 & 0.8 & 0.25 & 0 & 0 & 1000 \\
Max $^{\mathrm{b}}$ & 5 & 1.8 & 1.1 & 0.4 & 1.6 & 0.5 & 0.04 & 0.035 & 1100 \\
\hline
\end{tabular}

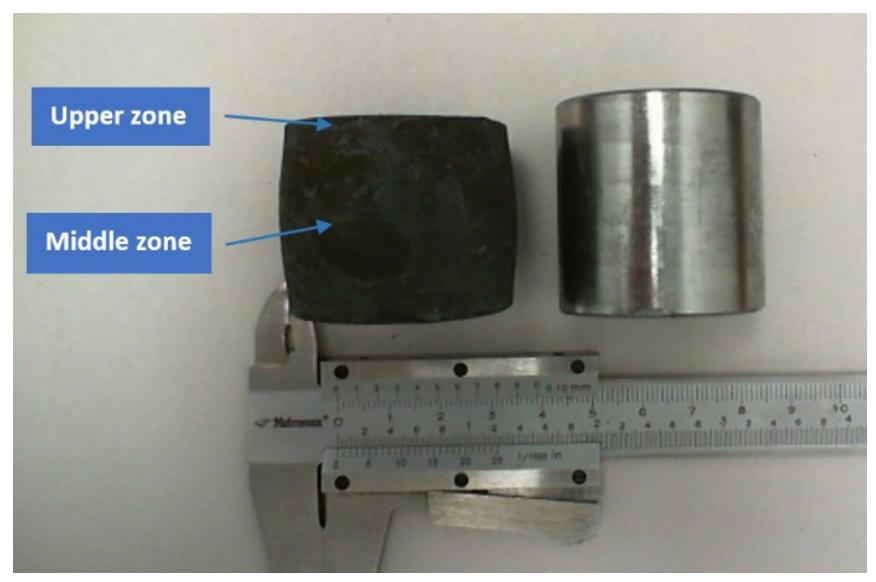

Figure 1. Deformed steel bar: initial diameter, $38.1 \mathrm{~mm}$; initial height, $44 \mathrm{~mm}$; final height, $40 \mathrm{~mm}$.

The thermal behavior of 8628 steel was investigated by means of a TA Instruments SDT Q600 differential scanning calorimeter (New Castle; UK) at a heating rate of $20^{\circ} \mathrm{C} / \mathrm{min}$. A constant flow of high-purity $\mathrm{Ar}$ and alumina sample holders were used. The sample masses were approximately $50 \mathrm{mg}$. The SDT Q600 was calibrated using an indium standard specimen $(\mathrm{Tm}=429.7 \mathrm{~K})$ and a zinc standard specimen $(\mathrm{Tm}=692.6 \mathrm{~K})$, giving an accuracy of $\pm 0.2 \mathrm{~K}$ and $\pm 0.2 \mathrm{~mW}$.

In order to locate the plastic strain zones and values, a FEM simulation of the deformation suffered by the steel bar was performed using Hypermesh software and the Radioss solver, along with a Johnson-Cook plastic model [15]. The three-dimensional geometry of one-fourth of the cylindrical geometry (90 degrees of the circle's area) was meshed in 
Hypermesh with 1980 tetra volume elements, establishing symmetry conditions to recreate the full cylinder's behavior, and constrained displacement in the axial direction $(\mathrm{z})$ for elements at the base of the cylinder and a $1 \mathrm{~mm} / \mathrm{s}$ imposed velocity on the top elements. Parameters for the Johnson-Cook model included E $=20 \mathrm{GPa}, v=0.3, \mathrm{~S}_{\mathrm{y}}=100 \mathrm{MPa}$, $\mathrm{S}_{\mathrm{u}}=150 \mathrm{MPa}, \varepsilon_{\mathrm{u}}=50 \%$, which are only approximate values, as the behavior of the steel at such a high temperature was only simulated to evaluate the distribution of the strain $\varepsilon$ and the strain rate $\dot{\varepsilon}$ (and not stress) along the section of the deformed cylinder. The Radioss solver was used to calculate these parameters for each element after $4 \mathrm{~s}$ and a $4 \mathrm{~mm}$ length reduction (reproducing the actual steel cylinder's hot deformation).

The longitudinal section of the forged steel bar was analyzed by cutting, grinding and polishing to perform Rockwell $\mathrm{C}$ hardness tests at the two zones indicated in Figure 1. Moreover, polished samples were etched with a $2 \%$ nital solution to observe the martensite and bainite in a Hitachi TM3030 SEM microscope $(15 \mathrm{kV})$, and thin samples were prepared to analyze the precipitates' presence in a JEOL JEM-1200EX Electron Microscope at $120 \mathrm{kV}$ along with diffraction patterns.

In order to simulate high-temperature precipitation occurring at the grain boundaries of the austenite phase at a temperature interval of $1000 \sim 1100{ }^{\circ} \mathrm{C}$, a 2-level design of experiments (DOE) was fed into Minitab statistical software using values much higher than the nominal ones (approximately twice as much for all elements except $\mathrm{C}$ and $\mathrm{Cr}$, for which the factor was $\sim 10$ times), which are presented in Table 2. Temperature was also considered a factor in the DOE simulation, as forging was carried out at $1100^{\circ} \mathrm{C}$, though cooling during this operation may have decreased the temperature to $\sim 1000^{\circ} \mathrm{C}$. Simulations were carried out using the Thermocalc TC-PRISMA precipitation module by feeding the program with the corresponding amount (weight \%) of the alloying element, temperature (either 1000 or $1100^{\circ} \mathrm{C}$ ) or an austenite iron FCC matrix, and tracing the precipitation of the $\mathrm{M}_{7} \mathrm{C}_{3}, \mathrm{M}_{23} \mathrm{C}_{6}$ or $\mathrm{MnS}$ phases in a $1000 \mathrm{~s}$ period, as hot forging manufacturing operations are performed at high speed many times in a few seconds for various deformation steps [1].

In all cases, the size of the calculated precipitates as a function of time, as well as the nucleation rate, were plotted and used in the Minitab results columns to generate DOE sensitivity plots. The TC-PRISMA module included in Thermocalc simulates the nucleation and growth of precipitates with a specific composition (TCFE8 database) in a metal matrix (in this case, $\gamma$-fcc Fe) using the Larger-Schwartz method and different values for the Gibbs energy $\left(\Delta G^{*}\right)$ for the formation of a critical nucleus [16].

A 2-level design of experiments was selected, as the number of independent factors included in the analysis was considerable (8 alloying element compositions and temperature) and a full experiment would require 512 trials. A 2-level fractional factorial design $(\alpha=0.05)$ was used, limiting the number of randomized experiments to 32 (a 1/16 fraction of the full factorial experiment $2^{9-4}$ ) and thus limiting the resolution of results to the interactions of 2 factors or a Level IV resolution (the main effect cannot be estimated separately from 3-factor interactions) [17]. The statistical results were considered adequate for this analysis and focused on the effect of each factor on the precipitation of specific particles.

\section{Results and Discussion}

The finite element simulation (Figure 2) indicated that maximum plastic strain was present at the middle (from bottom to top) of the steel bar and had a variation of $\varepsilon=12 \%$ at the center (axis) of the part to $7 \%$ at the exterior (surface of the bar). On the other hand, at the upper zone, deformation changed from zero at the center to $5 \%$ at the exterior zone. 


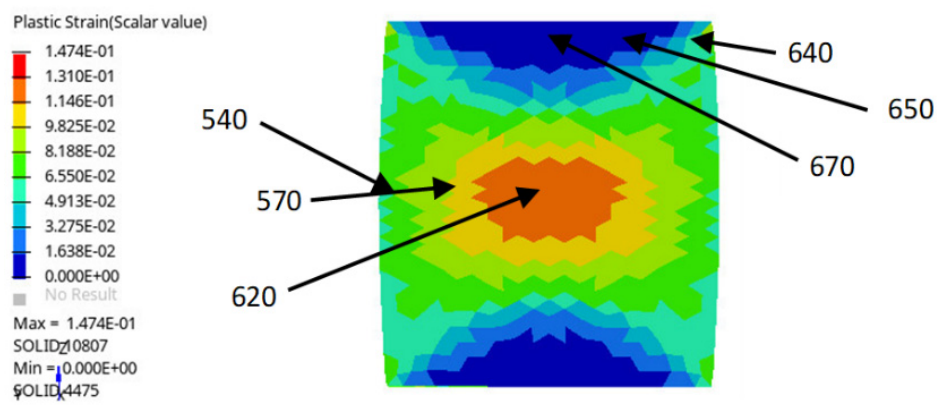

Figure 2. Radioss finite element dynamic simulation for the deformed billet. Plastic strain at the lower, middle, upper and center (axis) to exterior (surface) radius zones. Arrows indicate the average lamellar distance in $\mathrm{nm}$.

Figure 3 shows the third-grade polynomial curves fitted to Rockwell hardness measurements as a function of distance from the exterior surface of the bar at both the middle and upper zones of the hot deformed part. It was evident that the upper zone presented larger differences in hardness, though the cooling rates and martensite formation must also be taken into account, as the center of the bar suffers cooling at a slower rate than zones near to the surface.

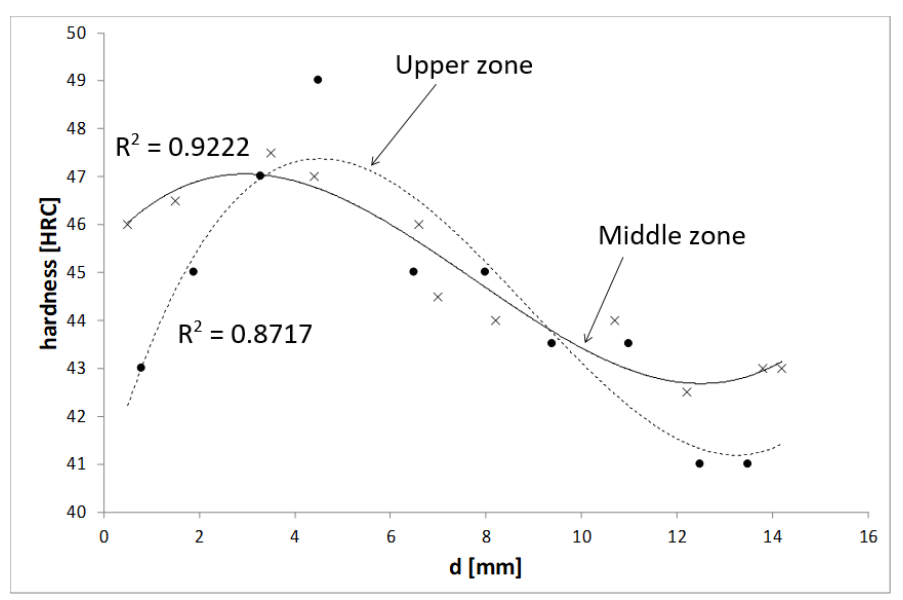

Figure 3. The 8620 steel deformed at $1100{ }^{\circ} \mathrm{C}$, with hardness as a function of distance from the surface.

If the lamellar spacing indicated in nm in Figure 4 is analyzed, it is difficult to connect strain or strain rate with the spacing of martensite or bainite as a function of the position in the deformed bar. On the other hand, this spacing, clearly related to hardness (Figure 2), with higher hardness when spacing is smaller [18], is a function of the cooling rate: zones near the surface will cool at a higher rate than those at the interior of the part. Moreover, differences in hardness were more evident at the upper zone (Figure 3), which suggests that PAGS is very important when defining the mechanical properties and that lamellar spacing is only part of the phenomenon.

Comparison of the martensite-bainite microstructure at the upper zone of the deformed bar (Figure 4) showed a clear difference in the previous austenite grain size and lamellar spacing: the zone in between the center and close to the surface (Figure $4 \mathrm{~b}$ ) showed smaller PAGS and smaller lamellar distancing, explaining the higher values in hardness.

On the other hand, at the middle zone from top to bottom of the bar, the microstructures at the center (Figure $5 a$ ) and between the center and the surface (Figure $5 b$ ) were very similar and clearly different from the zone near the surface (Figure 5c), just as expected from the finite element simulation. 

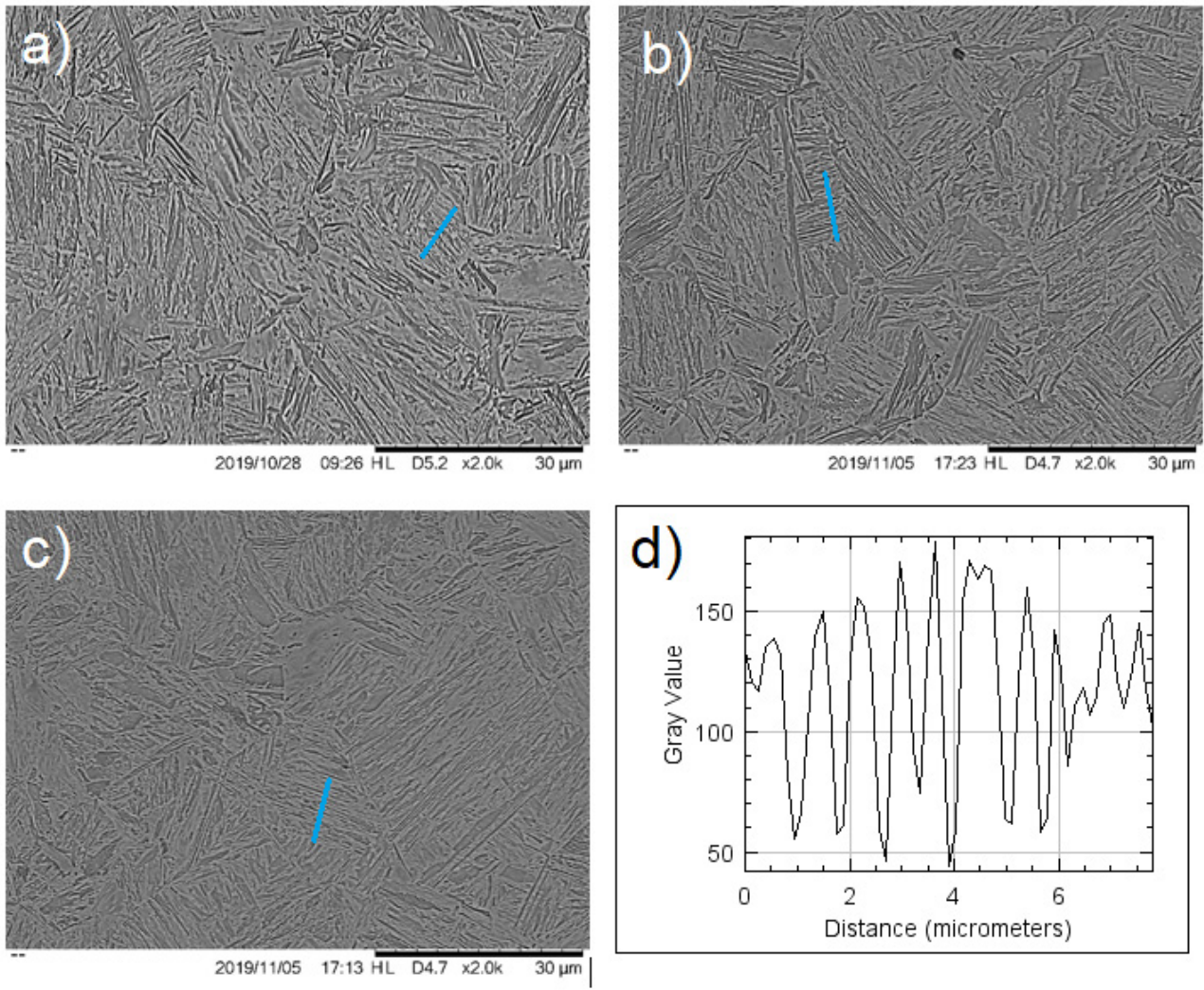

Figure 4. Micrograph of the upper zone for the deformed $\left(1100{ }^{\circ} \mathrm{C}\right)$ and quenched 8620 steel bar at the center (a), the middle (b) and near the surface (c), and lamellar spacing measurement at the center (d).
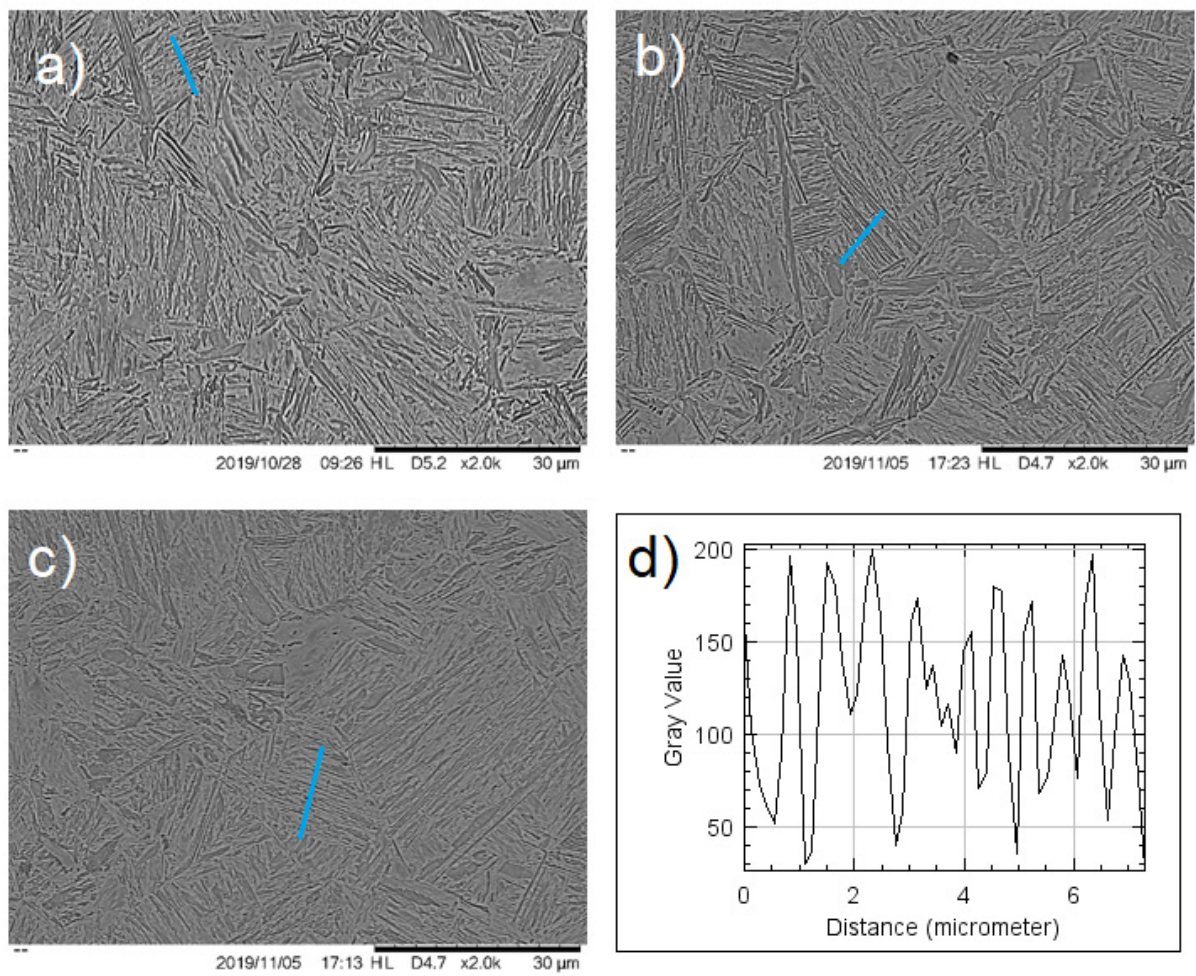

Figure 5. Micrograph of middle zone for the deformed $\left(1100{ }^{\circ} \mathrm{C}\right)$ and quenched 8620 steel bar at the center (a), the middle (b) and near the surface (c), and lamellar spacing measurement at the center (d). 
The lamellar spacing indicated in Figure 6, as a function of the distance from the surface of the hot deformed bar, showed a higher difference for the middle zone where, due to the larger difference in the strain and cooling rate, the spacing was expected to increase. However, Figure 3 shows that the variation in hardness was larger in the upper zone, which means that lamellar spacing is not the only factor to determine the mechanical properties and that PAGS is also important [12]. It is also important that the $95 \%$ confidence interval at the center of the bar was large for both zones, as this is a zone where the cooling rate is lower and the effect of strain in lamellar spacing is stronger.

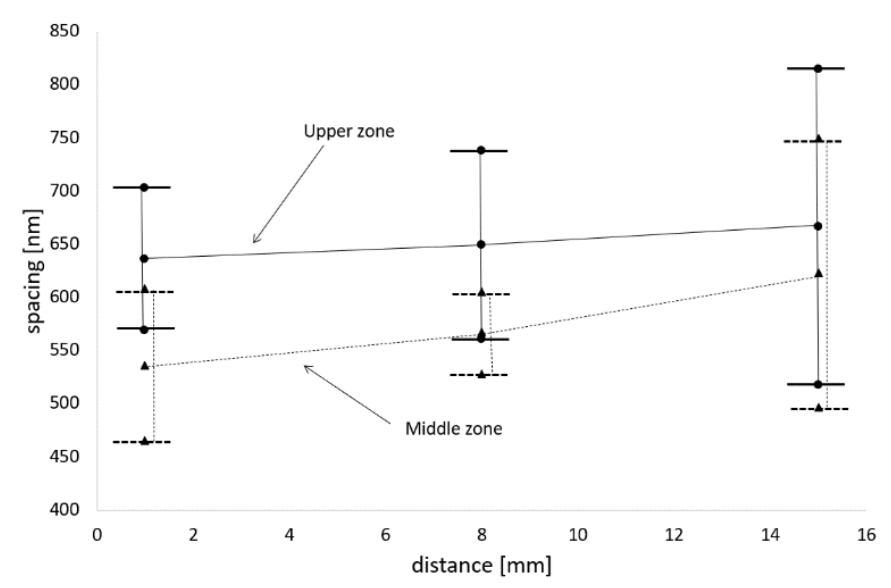

Figure 6. Lamellar spacing at different zones of the deformed steel bar (with $95 \%$ confidence level range) as a function of the distance from the surface.

DOE simulations in Thermocalc showed that $\mathrm{M}_{7} \mathrm{C}_{3}$ precipitates are clearly dependent on temperature (J factor in Figure 7) and that the alloying elements' content was close to the standardized distribution behavior.

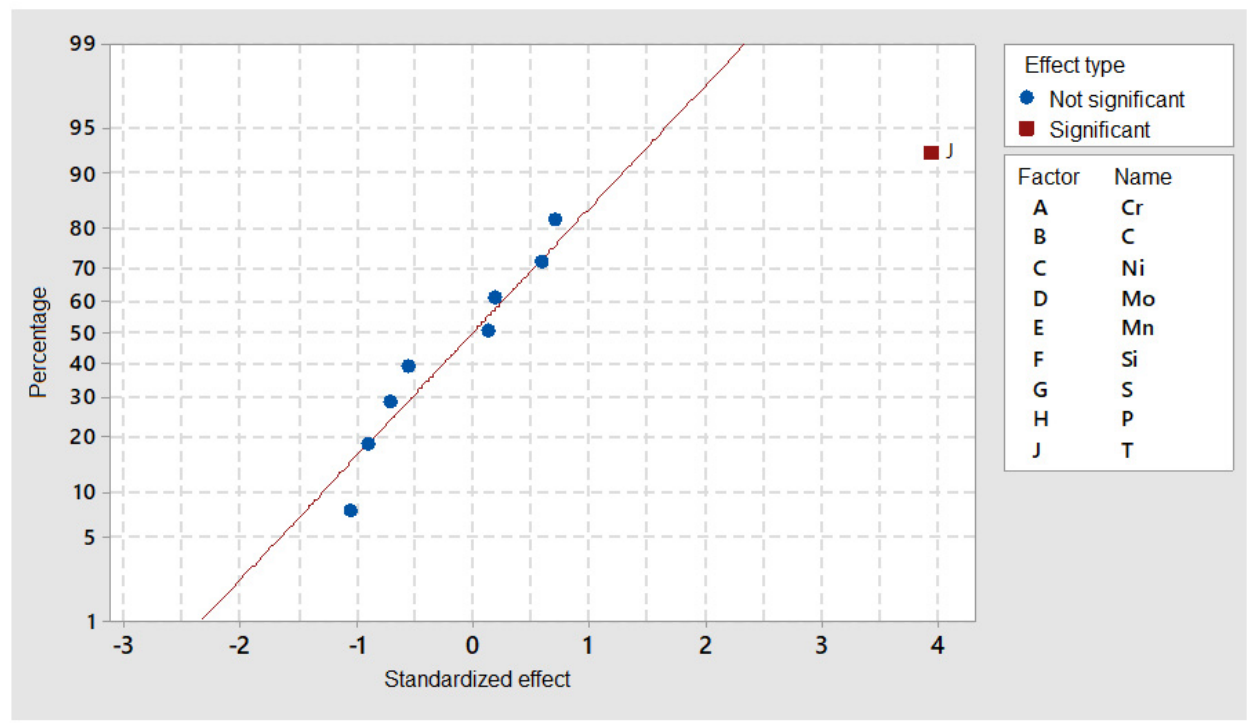

Figure 7. $\mathrm{M}_{7} \mathrm{C}_{3}$ precipitates' size in nanometers: standardized effects $(\alpha=0.05)$ for the DOE Thermocalc simulation.

Nevertheless, if precipitate size is considered (Figure 8), C and Si seemed to have a considerable effect, while $\mathrm{Cr}$ and Mo (elements forming the precipitate) did not show a significant effect. 


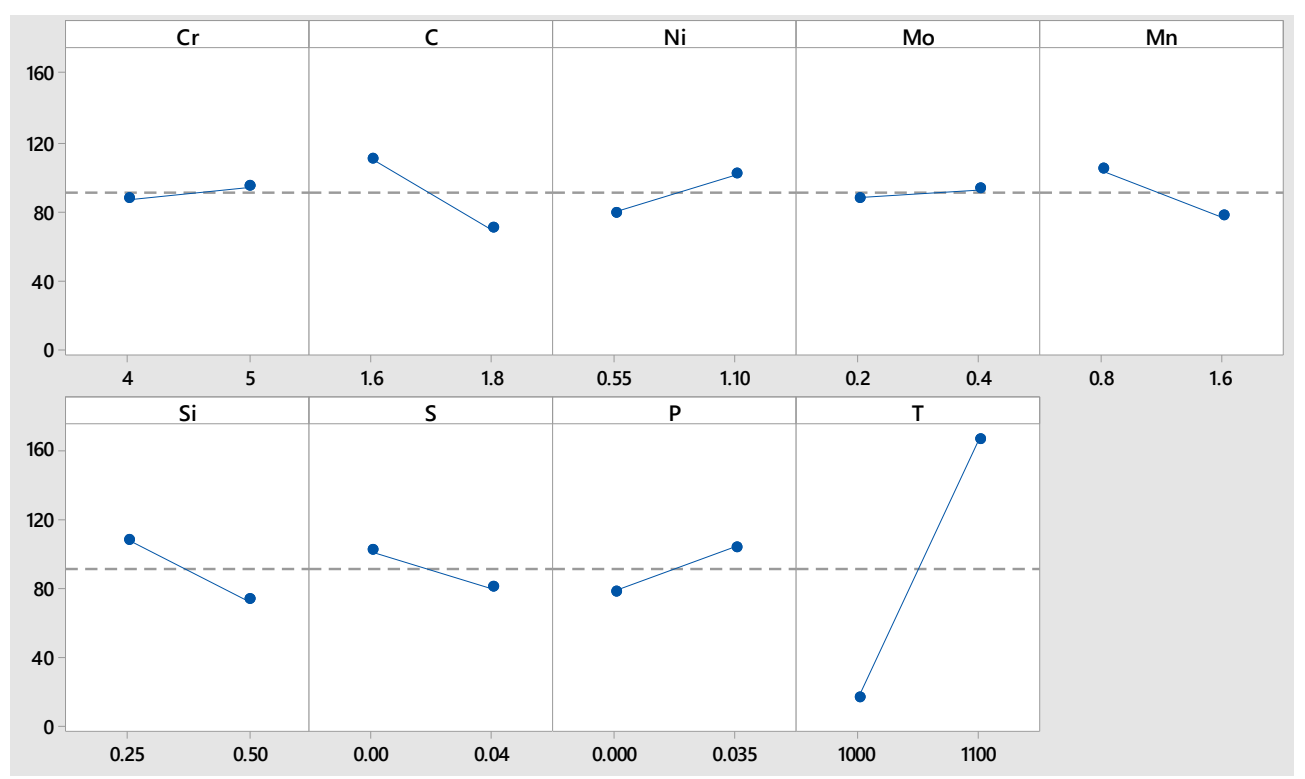

Figure 8. $\mathrm{M}_{7} \mathrm{C}_{3}$ precipitates' size in nanometers for the DOE Thermocalc simulation. Main average effects.

As expected, the nucleation rate for this precipitate was extremely low at $1100{ }^{\circ} \mathrm{C}$ and higher as the temperature decreased (Figure 9). This temperature interval, in which static and dynamic recrystallization phenomena may occur during hot forging, is greatly modified by nanometer-sized precipitation, which prevents grain growth.

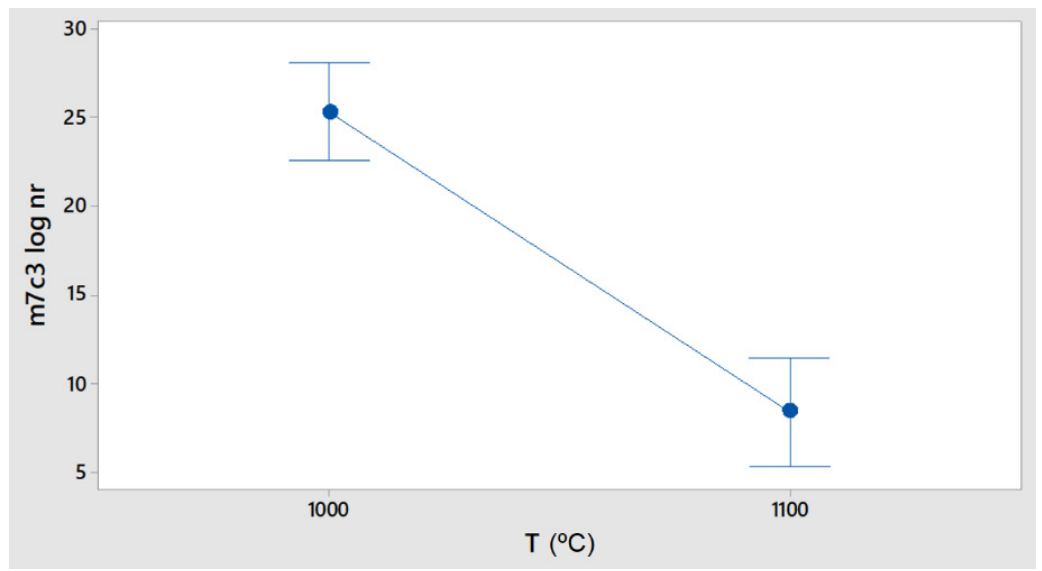

Figure 9. $\mathrm{M}_{7} \mathrm{C}_{3}$ precipitates' nucleation rate $\left(\mathrm{m}^{3} / \mathrm{s}\right)$ for the DOE Thermocalc simulation. Average effect of temperature $\left({ }^{\circ} \mathrm{C}\right)$.

Moreover, Figure 10 indicates that the nucleation rate is modified not only by temperature, but also by $\mathrm{Cr}$ and $\mathrm{C}$ content, i.e., the distribution of these two elements played a major role in the nucleation rate as the temperature decreased. 


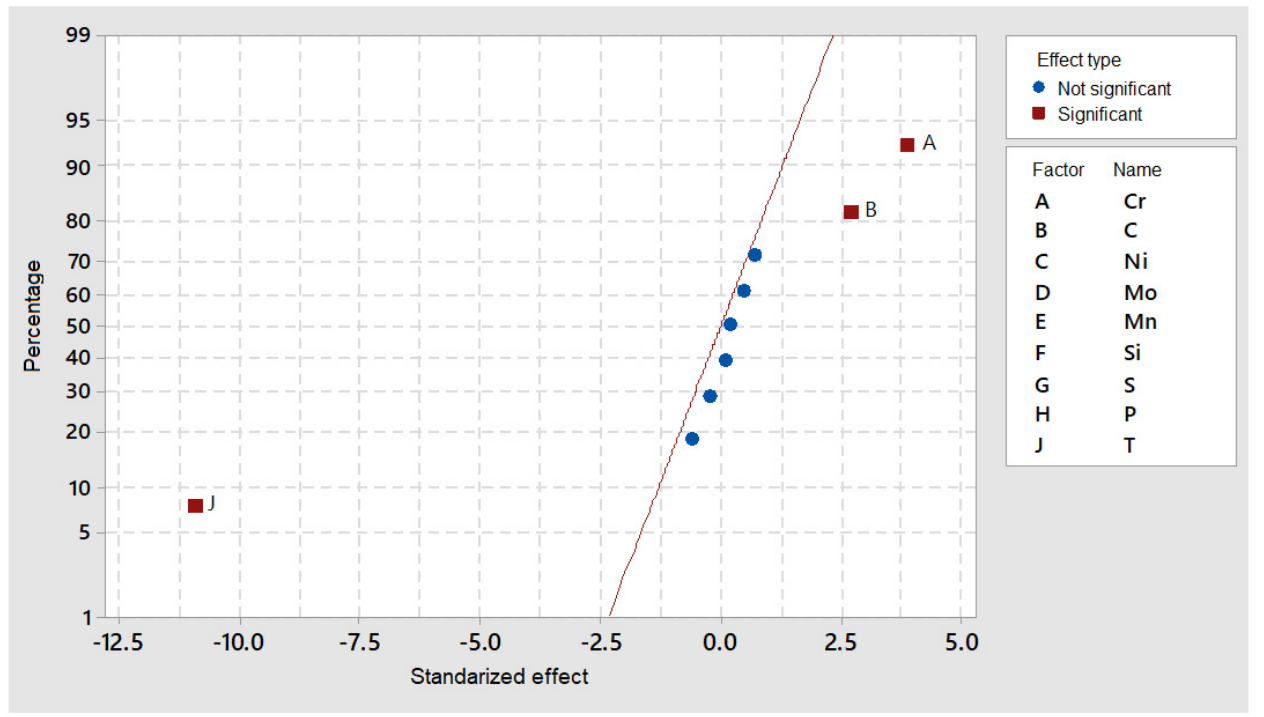

Figure 10. $\mathrm{M}_{7} \mathrm{C}_{3}$ precipitates' nucleation rate $\left(\mathrm{m}^{3} / \mathrm{s}\right)$ : standardized effects $(\alpha=0.05)$ for DOE Thermocalc simulation.

In the case of $\mathrm{M}_{23} \mathrm{C}_{6}$ precipitates, one of the most interesting results was that the maximum nucleation rate, which was null at $1100{ }^{\circ} \mathrm{C}$, occurred in a shorter time than $1000 \mathrm{~s}$, indicating this transient phase formed during cooling for very short periods of time. Figure 11 shows that the nucleation rate was significantly modified by the $\mathrm{Cr}$ and $\mathrm{C}$ content and that other alloying elements were also separated from the standardized distribution line.

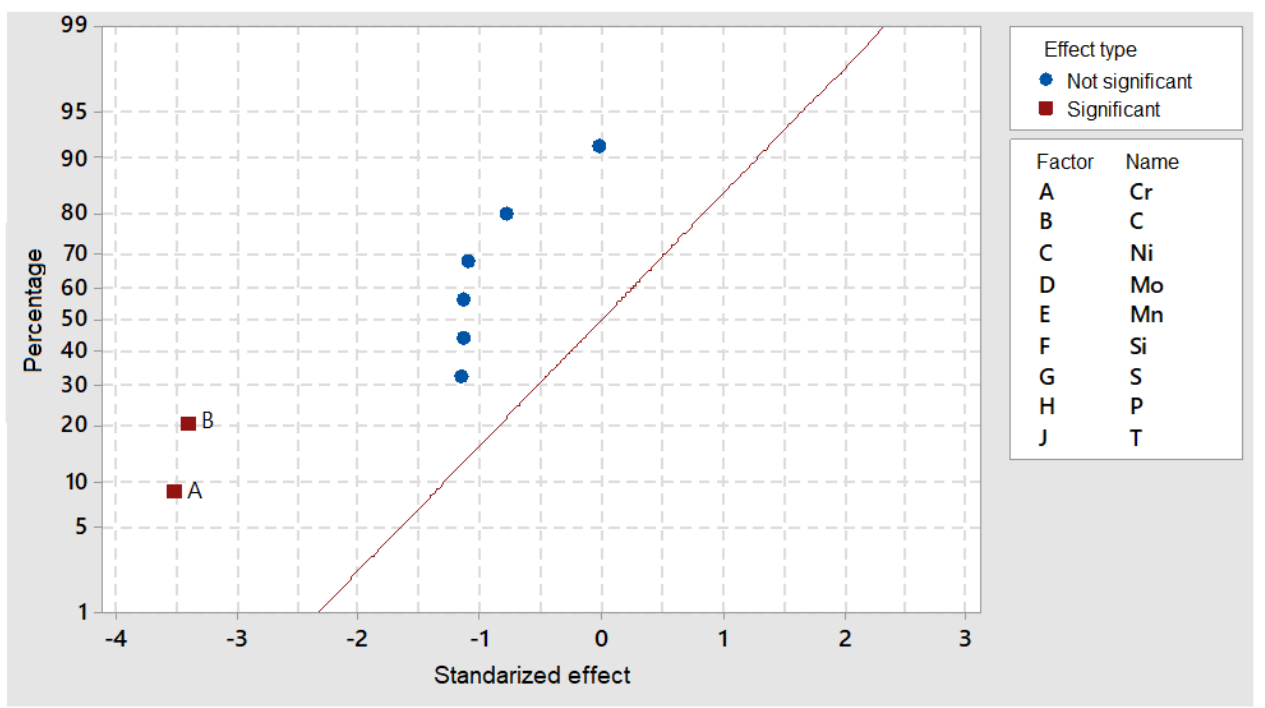

Figure 11. $\mathrm{M}_{23} \mathrm{C}_{6}$ precipitates' size in nanometers: standardized effects $(\alpha=0.05)$ for the DOE Thermocalc simulation.

The maximum percentages of precipitates, corresponding to the maximum nucleation time, as indicated in Figure 12, showed no interaction with Mn content and but the strong effects of $\mathrm{Cr}, \mathrm{C}$ and the other five elements. 


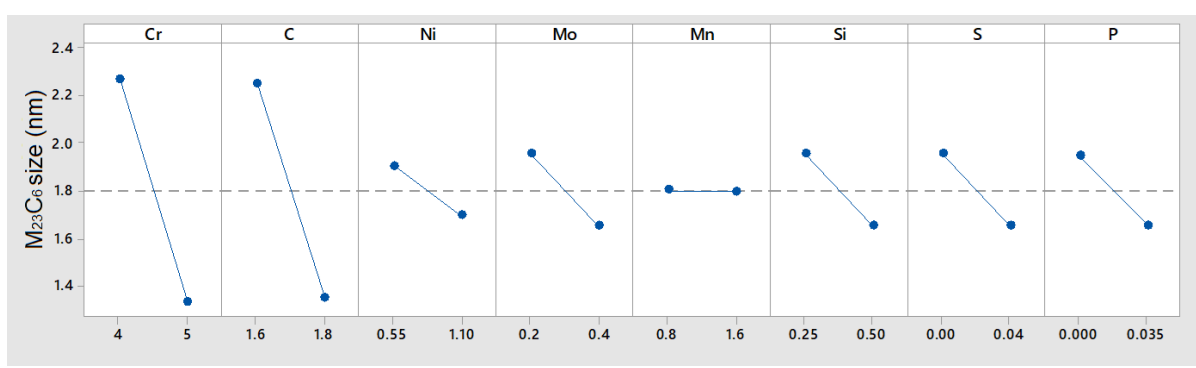

Figure 12. $\mathrm{M}_{23} \mathrm{C}_{6}$ precipitates' size in nanometers for the DOE Thermocalc simulation. Main average effects.

In the case of MnS precipitates (Figure 13), the simulation showed that these only appeared at $1100{ }^{\circ} \mathrm{C}$, while at $1000^{\circ} \mathrm{C}$, their size was negligible, which, during cooling, may directly affect the formation of $\mathrm{M}_{23} \mathrm{C}_{6}$ particles, as they are affected by $\mathrm{S}$ content.

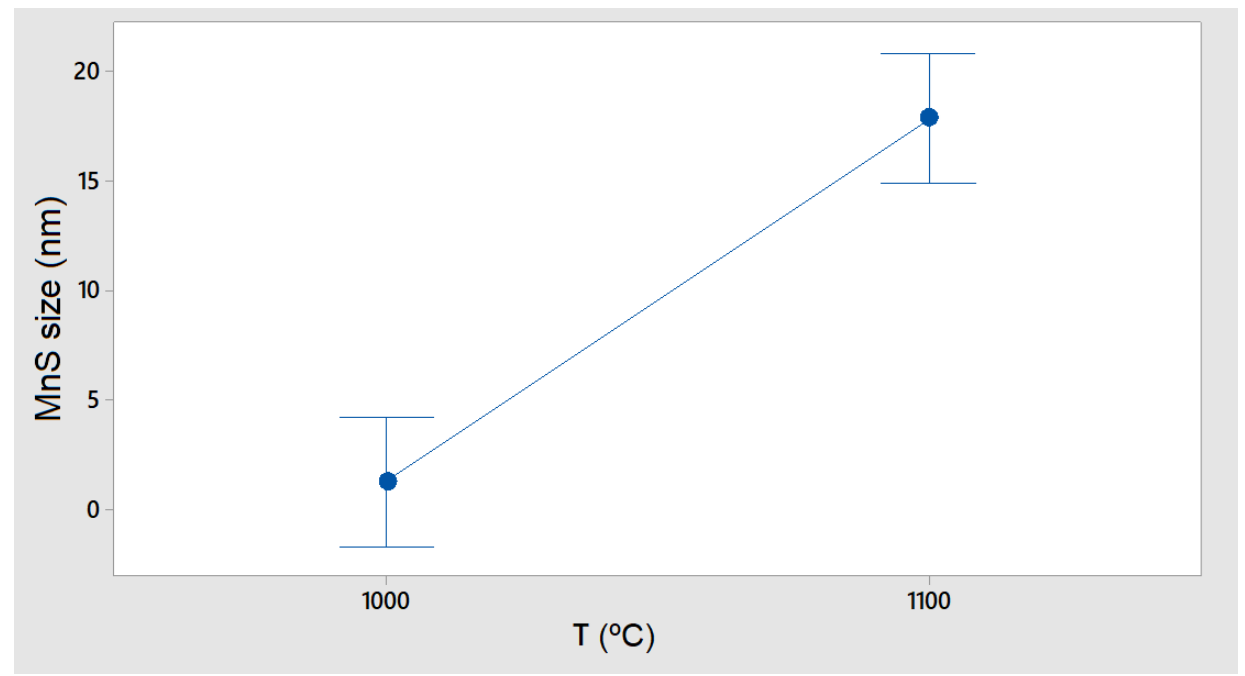

Figure 13. DOE Thermocalc simulation for MnS precipitates' size in nanometers as a function of $\mathrm{T}\left({ }^{\circ} \mathrm{C}\right)$.

The precipitation models $[19,20]$ indicated that, at $1100^{\circ} \mathrm{C}$, the hot forging deformation produced dynamic recrystallization. As Figure 2 indicates, the upper zone of the steel bar suffered a larger strain difference from zero to $\sim 8 \%$ which, combined with a more pronounced quenching effect (the surface in direct contact with the quenching fluid), resulted in more pronounced differences in the hardness curve (Figure 3). On the other hand, the curve for the middle section had smaller differences, as quenching was less effective and the strain gradient was only $\varepsilon=4 \%$, though this last curve in Figure 3 shows the highest values: deformations as high as $12 \%$ promoted dynamic recrystallization (XRD) and a smaller grain size, as shown by the PAGS in Figure 5c. Experimental tests of hotformed and cold-rolled samples of this steel [21] indicated that the amount of deformation influenced the diffusivity of carbon during surface cementation: a slower diffusivity of alloying elements is to be expected when strain is increased.

Another phenomenon to be considered is the chemical segregation of the alloying elements during the solidification of the steel. If the distribution coefficient $(k=\mathrm{Cs} / \mathrm{Cl})$ is larger than $1(k>1)$, individual grains will have large amounts of the element at the core of the grain and small amounts at the grain boundary. If, on the other hand, $k<1$, a small concentration of the element will be found at the center and an elevated amount at the boundary [22]. $\mathrm{Cr}$ and Mo, the precipitate-forming elements, have a $k$ of -1 , while $\mathrm{C}$ has a $k$ of 1 . This means that, at high temperature $\left(1100^{\circ} \mathrm{C}\right)$, the alloying elements at the grain boundary zones ( $\mathrm{Cr}$ and $\mathrm{Mo}$ ), combined with the larger capacity of $\mathrm{C}$ to move throughout the structure due to its size, may result in local concentrations which misrepresent the initial 
alloying content, i.e., local and very large amounts of $\mathrm{Cr}$ and Mo promote precipitation. Another possibility is that the $\mathrm{Cr} / \mathrm{C}$ ratio at these zones is so high that precipitation is promoted at a localized level. A comparison between the Thermocalc and observed precipitates in $4 \% \mathrm{Cr}$ steels [8] indicated that the software underestimated the size of the precipitates and overestimated their volume due to segregation at the grain boundaries.

Figure 14 shows the DSC curve for the 8620 steel sample at a heating rate of $20 \mathrm{~K} / \mathrm{min}$, indicating evident phase changes at $\sim 740^{\circ} \mathrm{C}$ and $\sim 880^{\circ} \mathrm{C}$, which correspond to the alphagamma and gamma-delta transformations. However, in the $1000 \sim 1100{ }^{\circ} \mathrm{C}$ temperature range the curve seems to be flat: a closer inspection reveals a slight depression in the curve, which may be connected to the fast appearance and dissolution of the precipitate phases. The Thermocalc simulation indicated that precipitates such as $\mathrm{M}_{7} \mathrm{C}_{3}$ were only present and reached their maximum size in short periods of time (100-1000 s). This is consistent with the hot forging manufacturing procedure, with deformation at $1100{ }^{\circ} \mathrm{C}$ and cooling in air at a $50 \sim 100{ }^{\circ} \mathrm{C} / \mathrm{min}$ rate.

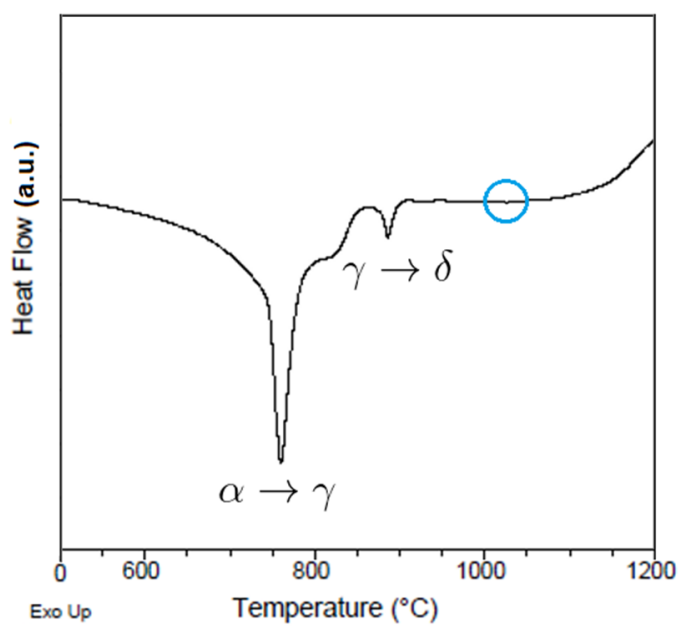

Figure 14. Thermal analysis of 8628 steel at a continuous heating rate of $20 \mathrm{~K} / \mathrm{min}$.

Figure 15a shows a TEM micrograph of the microstructure of the 8620 steel: several particles of different sizes can be observed within the ferrite matrix, with the biggest particles (nearly $500 \mathrm{~nm}$ ) corresponding to $\mathrm{Fe}_{3} \mathrm{C}$ (Figure 15b), whereas the smaller ones might be $\mathrm{M}_{7} \mathrm{C}_{3}$ or $\mathrm{M}_{23} \mathrm{C}_{6}$ carbides. The diffraction pattern overlaps perfectly with the calculated Debye rings for both carbides $\left(\mathrm{M}_{7} \mathrm{C}_{3}, \mathrm{M}_{23} \mathrm{C}_{6}\right)$, as indicated by Figure $15 \mathrm{c}$, d. The selected area chosen for diffraction has been marked by a circle. Furthermore, the corresponding indexation for each carbide is shown (from the inner to outer rings). The result mentioned above is compatible with the Calphad prediction of carbide formation at high temperatures due to chemical segregation at the grain boundaries.

Steels used in hot forging operations are expected to maintain a small grain size, as subsequent operations such as surface treatments are effective only if the grain size is small enough to produce hardened localized zones [23]. The $1000 \sim 1100{ }^{\circ} \mathrm{C}$ temperature interval, most commonly used in hot forging operations for 8620 steel, is expected to have limited grain growth by static recrystallization and to maintain grain size by means of XRD. However, yet the role of $\mathrm{Cr}$, Mo and $\mathrm{Mn}$ as precipitate-forming elements is not clear, as the amounts of the alloying elements were too low to explain the appearance of nanometric particles at this temperature, which is the only plausible explanation for grain growth inhibition by pinning mechanisms. 

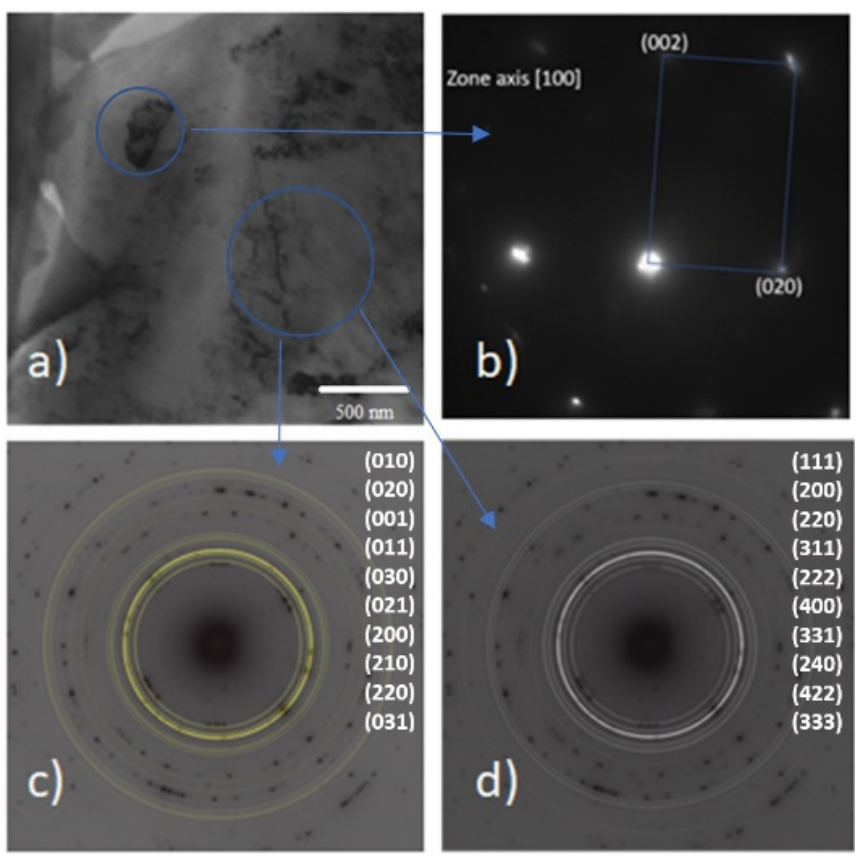

c)

Figure 15. (a) TEM image (bright field) and diffraction patterns of characteristic precipitates in 8620 steel deformed and quenched at $1100{ }^{\circ} \mathrm{C}$. (b) Diffraction pattern of $\mathrm{Fe}_{3} \mathrm{C}$, (c) diffraction rings compatible with $\mathrm{M}_{7} \mathrm{C}_{3}$ and (d) diffraction rings compatible with $\mathrm{M}_{23} \mathrm{C}_{6}$.

\section{Conclusions}

Thermocalc simulations along with DOE of localized zones with very high concentrations of $\mathrm{Cr}$ and Mo at austenite grain boundaries showed precipitates forming in a short time in the $1000 \sim 1100{ }^{\circ} \mathrm{C}$ interval that may be responsible for maintaining the small grain size needed in forging operations, as the 8620 steel is to receive other transformations and surface-modifying operations, which can only be performed in steels with a small grain size.

The presence of small precipitates of the $\mathrm{M}_{7} \mathrm{C}_{3}$ and $\mathrm{M}_{23} \mathrm{C}_{6}$ kind, indicated by the electron diffraction patterns, may be considered as evidence of the segregation of the alloying elements during hot forming deformation, though this is very hard to detect, as the precipitates are nanometric in size and completely disappear as the temperature decreases.

Author Contributions: R.G.-O. designed the general structure of the article while performing the experimental tests and Thermocalc and Minitab simulations. O.L.-F. helped Roberto González with the preparation of samples, and specifically performed the SEM micrograph analyses and TEM preparation and analyses, as well as measurement of the DSC results. G.G.-R. interpreted the TEM micrographs and diffraction patterns while also performing a general revision of the text. J.M.S.-M. designed the simulation procedure and revised the text. All four authors were responsible for text preparation and final formatting. All authors have read and agreed to the published version of the manuscript.

Funding: This research received no external funding.

Data Availability Statement: Information regarding the work may be provided upon request.

Acknowledgments: The authors wish to thank the FFIUP program at Universidad Panamericana and the help of Carlos Flores for the use of the TEM and DSC equipment at UNAM.

Conflicts of Interest: The authors declare no conflict of interest. 


\section{References}

1. Verdeja, L.F.; Verdeja, J.I.; González, R. Machinability Improvement through Heat Treatment in 8620 Low-Carbon Alloyed Steel. Mach. Sci. Technol. 2009, 13, 529-542. [CrossRef]

2. Zhang, Y.-J.; Hui, W.; Dong, H. Hot Forging Simulation Analysis and Application of Microalloyed Steel Crankshaft. J. Iron Steel Res. Int. 2007, 14, 189-194. [CrossRef]

3. Wieczerzak, K.; Bała, P. Hypoeutectic Fe-Cr-Ni-Mo-C alloys additionally strengthened by the Frank-Kasper phases-Design by means of the CALPHAD approach. Calphad 2019, 64, 248-257. [CrossRef]

4. Zhu, N.-Q.; Lu, L.; He, Y.-L.; Li, L.; Lu, X.-G. Coarsening of $\mathrm{M}_{23} \mathrm{C}_{6}$ Precipitates in an Fe-Cr-C Ternary Alloy. J. Iron Steel Res. Int. 2012, 19, 62-67. [CrossRef]

5. Wen, T.; Hu, X.; Song, Y.; Yan, D.; Rong, L. Carbides and mechanical properties in a Fe-Cr-Ni-Mo high-strength steel with different V contents. Mater. Sci. Eng. A 2013, 588, 201-207. [CrossRef]

6. Park, S.-G.; Kim, M.-C.; Lee, B.-S.; Wee, D.-M. Correlation of the thermodynamic calculation and the experimental observation of Ni-Mo-Cr low alloy steel changing Ni, Mo, and Cr contents. J. Nucl. Mater. 2010, 407, 126-135. [CrossRef]

7. Ernst, F.; Li, D.; Kahn, H.; Michal, G.M.; Heuer, A.H. The carbide $\mathrm{M}_{7} \mathrm{C}_{3}$ in low-temperature-carburized austenitic stainless steel. Acta Mater. 2011, 59, 2268-2276. [CrossRef]

8. Hou, Z.; Hedström, P.; Chen, Q.; Xu, Y.; Wu, D.; Odqvist, J. Quantitative modeling and experimental verification of carbide precipitation in a martensitic Fe-0.16wt\%C-4.0wt\%Cr alloy. Calphad 2016, 53, 39-48. [CrossRef]

9. Prat, O.; Garcia, J.; Rojas, D.; Carrasco, C.; Kaysser-Pyzalla, A. Investigations on coarsening of MX and $\mathrm{M}_{23} \mathrm{C}_{6}$ precipitates in $12 \%$ Cr creep resistant steels assisted by computational thermodynamics. Mater. Sci. Eng. A 2010, 527, 5976-5983. [CrossRef]

10. Kaneko, K.; Fukunaga, T.; Yamada, K.; Nakada, N.; Kikuchi, M.; Saghi, Z.; Barnard, J.; Midgley, P. Formation of M $_{23} C_{6}$-type precipitates and chromium-depleted zones in austenite stainless steel. Scr. Mater. 2011, 65, 509-512. [CrossRef]

11. Graux, A.; Cazottes, S.; De Castro, D.; Martín, D.S.; Capdevila, C.; Cabrera, J.M.; Molas, S.; Schreiber, S.; Mirković, D.; Danoix, F.; et al. Precipitation and grain growth modelling in Ti-Nb microalloyed steels. Material 2019, 5, 100233. [CrossRef]

12. Zheng, Y.; Wang, F.; Li, C.; Li, Y.; Cheng, J.; Cao, R. Effect of Microstructure and Precipitates on Mechanical Properties of Cr-Mo-V Alloy Steel with Different Austenitizing Temperatures. ISIJ Int. 2018, 58, 1126-1135. [CrossRef]

13. Giordani, T.; Clarke, T.R.; Kwietniewski, C.E.F.; Aronov, M.A.; Kobasko, N.I.; Totten, G. Mechanical and Metallurgical Evaluation of Carburized, Conventionally and Intensively Quenched Steels. J. Mater. Eng. Perform. 2013, 22, 2304-2313. [CrossRef]

14. Pearson, A.D. SAE Ferrous Materials Standards Manual-2004 Edition HS-30/2004; SAE International: Warrendale, PA, USA; ISBN 978-0-7680-1313-9.

15. Murugesan, M.; Jung, D.W. Johnson Cook Material and Failure Model Parameters Estimation of AISI-1045 Medium Carbon Steel for Metal Forming Applications. Material 2019, 12, 609. [CrossRef] [PubMed]

16. Sanhueza, J.P.; Rojas, D.; Prat, O.; Garcia, J.; Espinoza, R.; Montalba, C.; Melendrez, M. Precipitation kinetics in a $10.5 \%$ Cr heat resistant steel: Experimental results and simulation by TC-PRISMA/DICTRA. Mater. Chem. Phys. 2017, 200, 342-353. [CrossRef]

17. Gonzalez, R.; Quintana, M.J.; Verdeja, L.F. Dmaic of structural steel parts through FEM and DOE. OPENAIRE 2016, 1, 481-490.

18. Odnobokova, M.; Belyakov, A.; Enikeev, N.; Kaibyshev, R.; Valiev, R.Z. Microstructural Changes and Strengthening of Austenitic Stainless Steels during Rolling at 473 K. Metals 2020, 10, 1614. [CrossRef]

19. Gui, L.; Long, M.; Zhang, H.; Chen, D.; Liu, S.; Wang, Q.; Duan, H. Study on the precipitation and coarsening of TiN inclusions in Ti-microalloyed steel by a modified coupling model. J. Mater. Res. Technol. 2020, 9, 5499-5514. [CrossRef]

20. Yang, Y.; Zhao, X.-M.; Dong, C.-Y.; Zhao, X.-Y. Influence of Hot Deformation and Precipitates on the Recrystallization of Nb-V-Ti Free-Cutting Steel. Metals 2020, 10, 1587. [CrossRef]

21. Yeğen, İ.; Usta, M. The effect of salt bath cementation on mechanical behavior of hot-rolled and cold-drawn SAE 8620 and 16MnCr5 steels. Vacuum 2010, 85, 390-396. [CrossRef]

22. Porter, D.A.; Easterling, K.E. , Sherif, M.Y. Phase Transformations in Metals and Alloys, 3rd ed.; CRC Press: Boca Raton, FL, USA, 2009 ; pp. 1-521.

23. Roy, S.; Zhao, J.; Shrotriya, P.; Sundararajan, S. Effect of laser treatment parameters on surface modification and tribological behavior of AISI 8620 steel. Tribol. Int. 2017, 112, 94-102. [CrossRef] 